\title{
聴性脳幹誘発電位からみたクモ膜下出血重症例の病態
}

\author{
中村 正直, 塩貝 敏 之, 佐久間 正 \\ 原充弘, 小柏 元 英, 竹内一夫
}

\section{Clinical Analysis of Brainstem Auditory Evoked Potentials (BAEPs) in Severe Subarachnoid Hemorrhage Patients}

Masanao Nakamura, M.D., Toshiyuki Shiogai, M.D., Tadashi Sakuma, M.D., Mitsuhiro Hara, M.D., Motohide OGashiwa, M.D., and Kazuo Takeuchi, M.D.

Department of Neurosurgery, Kyorin University School of Medicine, Tokyo, Japan

Summary : Auditory brainstem evoked potentials (BAEPs) reflect activities of the brainstem auditory pathway and its surrounding structures. It is said that BAEPs are reliable indicators of the prognosis of patients with severe brain damage. We studied the relationship between initial BAEP findings, particularly interpeak latencies of waves I to V and waves III to V, and mortality resulting from severe subarachnoid hemorrhage.

BAEPs were sequentially recorded in 76 cases of severe subarachnoid hemorrhage (Hunt \& Kosnik grade IV, V) during the first few days after onset.

BAEPs were graded into four groups based on initial findings. Group A: waves I to V were all recorded (41 cases). Group B: waves IV \& V were absent ( 3 cases). Group C: either wave I or waves I \& II only were recorded (12 cases). Group D: all waves absent. Prognosis in Groups B \& C was poor, with only one patient surviving in a vegetable state. There were no survivors in Group D.

The relationship between interpeak latencies (I-V ipl, III-V ipl) and prognosis in Group A is discussed in this paper. In cases where severe subarachnoid hemorrhage resulted in death, there was significant prolongation of I-V ipl and III-V ipl over the mean latency of 20 normal subjects plus 2SD. The difference in initial BAEP findings between the dead and survivors was significant $(p<0.001)$. We reasoned that severe subarachnoid hemorrhage cases received primary brainstem damage and secondary brainstem damage due to increased intracranial pressure associated with acute cerebral swelling. We therefore concluded that poor prognosis could be predicted based on initial BAEP findings.

On the other hand, in acute hydrocephalus cases latencies were recovered by ventricular drainage. Continuous BAEP monitoring was therefore considered to be useful for predicting the effect of ventricular drainage in acute hydrocephalus.

BAEP monitoring appears to be a useful clinical indicator of prognosis of severe subarachnoid hemorrhage. Prolonged interpeak latencies of over mean plus 2SD can indicate poor prognosis in severe subarachnoid hemorrhage.
Key words :

- subarachnoid hemorrhage

- brainstem auditory evoked potentials 


\section{はじめに}

重症脳障害患者の予後推定，およびその脳幹機能の客観 的評価を目的に, 聴性脳幹誘発電位 (brainstem auditory evoked potentials, 以下 BAEP) が臨床に広く応用されてい る. しかし, 報告の多くは重症頭部外傷に関するもので, 脳血管障害とくにクモ膜下出血重症例の脳幹機能を BAEP モニタリングから評価した論文は少ない1)2). 今回 われわれは, クモ膜下出血重症例 (Hunt \& Kosnik grade IV,V)にBAEP モニタリングを行い，その有用性を検討 したので報告する.

\section{対象と方法}

対象は，杏林大学脳神経外科および救命救急センターに て, 入院 ·加療した Hunt \& Kosnik grade IV, V, Glasgow coma score (GCS) 8 以下のクモ膜下出血76例 (男性 28 , 女 性48)である. 年齢は33〜84歳，平均56歳である.

BAEP 測定は，MEB 5100 (日本光電社製)を使用し，皿 電極にて $\mathrm{Fz}$ を接地電極, $\mathrm{C} z$ と両側耳介との双極誘導と

Table 1 Normal peak latencies and normal interpeak latencies of auditory brainstem evoked potentials (BAEPs)

Normal latencies (msec) 90 dBHL $(n=20)$

\begin{tabular}{ccccccccc}
\hline Wave & I & II & III & IV & V & I - II & III - V & I-V \\
\hline $\begin{array}{c}\text { Mean } \\
\text { latency }\end{array}$ & 1.48 & 2.77 & 3.72 & 5.00 & 5.54 & 2.23 & 1.83 & 4.05 \\
S.D. & 0.072 & 0.094 & 0.083 & 0.16 & 0.19 & 0.094 & 0.14 & 0.18 \\
\hline
\end{tabular}

\begin{tabular}{|c|c|c|c|c|}
\hline \multicolumn{5}{|c|}{ Normal interpeak latencies (msec) } \\
\hline & $-2 \mathrm{SD}$ & $-\mathrm{SD}$ & $+\mathrm{SD}$ & \\
\hline & & 1 & & \\
\hline$I-1$ & 3.69 & 3.87 & 4.23 & 4.41 \\
\hline
\end{tabular}

した。刺激は $90 \mathrm{~dB}$ HL alternating click を両側同時刺激 し, low cut $100 \mathrm{~Hz}$, high cut $3 \mathrm{kHz}$ にて2048回加算し, XY recorder に記録した。

測定時期は全例搬入直後あるいは，手術後可及的早期か ら開始し，30分間隔の連続的または，継時的にBAEP モ ニタリングを行った。なお対照は健康成人 20 例を測定し, その BAEP 各潜時，頂点間潜時の mean $\pm 2 \mathrm{SD}$ を正常範 囲とした。

脳幹機能の変化は急性期の $\mathrm{I}-\mathrm{V}$ 波間潜時 (以下 $\mathrm{I}-\mathrm{V}$ ipl), III-V 波間潜時 (以下 III-V ipl) を指標とした. また予後に 関し, 全例退院時または 3 か月後の生存群, 死亡群に大別 した。そしてそれぞれの初回 BAEP 記録時の波形と, Glasgow outcome scale (GOS) からみた生命予後を比較検 討した.ささらに各潜時を生存群, 死亡群に分けて, これら を正常範囲と対比し，各潜時・波形の推移と生命予後との 関連を検討した。 また，急性水頭症合併例の脳室ドレナー ジによる頭蓋内減圧効果の影響も検討した. なお，低体温 時 $\left(35^{\circ} \mathrm{C}\right.$ 以下) の記録は各潜時の延長を示す ${ }^{3)}$ ため対象外と した.

\section{結 果}

\section{1. 初回 BAEP 波形の検討}

初回 BAEP の波形から A D の 4 群に分類し, 各群と 生命予後について検討した (Table 2).A 群 (41例) は，初 回記録時の $\mathrm{BAEP}$ で $\mathrm{I} \sim \mathrm{V}$ 波が明確に同定可能なもの, B 群 ( 3 例) は, I〜III 波の記録のみで IV, V 波の認められ ないもの, $\mathrm{C}$ 群 (12例) は I 波のみ，または I, II 波のみの もの, D 群 (20例) は, 既に $\mathrm{I} \sim \mathrm{V}$ 波がすべて消失し平坦な ものである.

A 群の搬入時 GCS は $3 \sim 8$, また GOS は good 1 例, moderate disability 1 例, severe disability 2 例, vegetable 4 例の計 8 例のみが生存し，33例は死亡した. 一方,

Table 2 Analysis of initial BAEP findings in severe subarachnoid hemorrhage cases. BAEPs were graded into four groups based on initial findings.

\begin{tabular}{|c|c|c|c|c|c|c|c|c|c|c|c|c|}
\hline \multirow{2}{*}{$\begin{array}{l}\text { Group of } \\
\text { initial BAEP }\end{array}$} & \multirow[b]{2}{*}{ cases } & \multicolumn{5}{|c|}{ Initial GCS } & \multirow[b]{2}{*}{3} & \multicolumn{4}{|c|}{ GOS } & \multirow[b]{2}{*}{$\mathrm{D}$} \\
\hline & & $\geq 8$ & 7 & 6 & 5 & 4 & & G & MD & $\mathrm{SD}$ & V & \\
\hline A $[\mathrm{PI}-\mathrm{PV}(+)]$ & 41 & 5 & 4 & 11 & 6 & 13 & 2 & 1 & 1 & 2 & 4 & 33 \\
\hline $\mathrm{B}\left[\begin{array}{l}\mathrm{PI}-\mathrm{PIII}(+) \\
\mathrm{PIV}, \mathrm{PV}\end{array}{ }_{(-)}\right]$ & 3 & 0 & 0 & 0 & 0 & 1 & 2 & 0 & 0 & 0 & 0 & 3 \\
\hline $\mathrm{C}\left[\begin{array}{l}\text { only PI } \\
\text { or PI, III }\end{array}\right]$ & 12 & 0 & 0 & 0 & 0 & 4 & 8 & 0 & 0 & 0 & 1 & 11 \\
\hline D flat & 20 & 0 & 0 & 0 & 0 & 0 & 20 & 0 & 0 & 0 & 0 & 20 \\
\hline & 76 & 5 & 4 & 11 & 6 & 18 & 32 & 1 & 1 & 2 & 5 & 67 \\
\hline
\end{tabular}

Group A: all waves I to V were recorded ( 41 cases). Group B: waves IV\&V were absent ( 3 cases). Group C: either wave I or waves I \& II only were recorded (12 cases). Group D: all waves were absent. Prognoses in Groups B,C,D were poor, with only one patient surviving in a vegetable state. There is no corelation between initial GCS and GOS. 
$\mathrm{B} \cdot \mathrm{C} \cdot \mathrm{D}$ 群の搬入時 GCS は全例 $3 ， 4$ と極めて不良で, GOS も植物状態 1 例を除き, 他はすべて死亡した。した がって, 初回 BAEP 記録時 B・C・D 群の予後は, 絶対 的不良と判定された. しかし，A 群の場合 $\mathrm{I} \sim \mathrm{V}$ 波の出現 という波形診断のみから生命予後・機能予後を推定するこ とは困難である。

\section{2. 急性期 $I-V$ ipl ・ III-V ipl と予後の検討}

A 群 (41例)の急性期 I-V ipl ・ III-V ipl を生存群, 死亡 群別に測定し, 正常範囲と比較検討した (Fig. 1). 生存群 の I-V ipl・III-V ipl ともに正常範囲に比べ, 各潜時に有 意差はない. しかし, 死亡群では I-V ipl・III-V ipl とも に急性期からすでに正常範囲上限またはそれ以上に延長し $(p<0.01)$, その平均潜時は I-V ipl $4.40 \mathrm{msec,} \mathrm{III-V} \mathrm{ipl}$ $2.20 \mathrm{msec}$ である. さらに, 生存群, 死亡群の比較でも, 死亡群の I-V ipl は生存群より有意に延長し $(p<0.01)$, III-V ipl も延長傾向がある $(p<0.1)$.

以下に代表例を呈示する。

59 歳女性, Hunt \& Kosnik grade V, Fisher type IV (Fig. 2). 搬入時 GCS 4, BAEP では I〜V 波の波形分離 は良いが, I-V ipl は両側とも $4.60 \mathrm{msec}$ を越え, III-V ipl も $2.40 \mathrm{msec}$ 以上に延長していた.さらにBAEPの継 時的測定では, III 波以後が急速に消失し死亡している. すなわち, 死亡群では生存群に比べ急性期, すでに強い脳 幹機能の障害がBAEPにより示唆され，この推移から予 後が予測できた例である.

\section{3. 潜時・波形の継時的変化の検討}

初回各潜時が正常の場合の潜時 - 波形の継時的変化を検 討した. 死亡群 (Fig. 3)の潜時・波形の変化で, I-V ipl は 継時的に徐々に正常範囲以上に延長し, 急速に B・C・D 群へ変化した. 生存群 (Fig. 4)の I-V ipl は, 常に正常範 囲内で推移した. したがって, 初回 BAEP で各潜時の延 長を認めない場合にも連続的 BAEP モニタリングによる 潜時・波形の推移・変化が重要で, 継時的に I-V ipl が正 常範囲以上に延長する場合の予後は不良である.

\section{4. 急性水頭症合併例に対する検討}

急性水頭症合併による頭蓋内圧方進時に, 脳室ドレナー ジを施行した症例の BAEPを検討した. Fig. 5 に示す 2 例では, I-V ipl は脳室ドレナージ施行後 $2 \sim 3$ 日で正常 範囲内へ回復し, 意識レベルも改善している. しかし, 再 出血・脳血管攣縮のため再び BAEP は潜時・波形が急速 に悪化した。 また54歳男性, 右脳梁周囲動脈瘤破裂, 脳 内・脳室内出血例 (Fig. 6) では, 脳室ドレナージの開放,

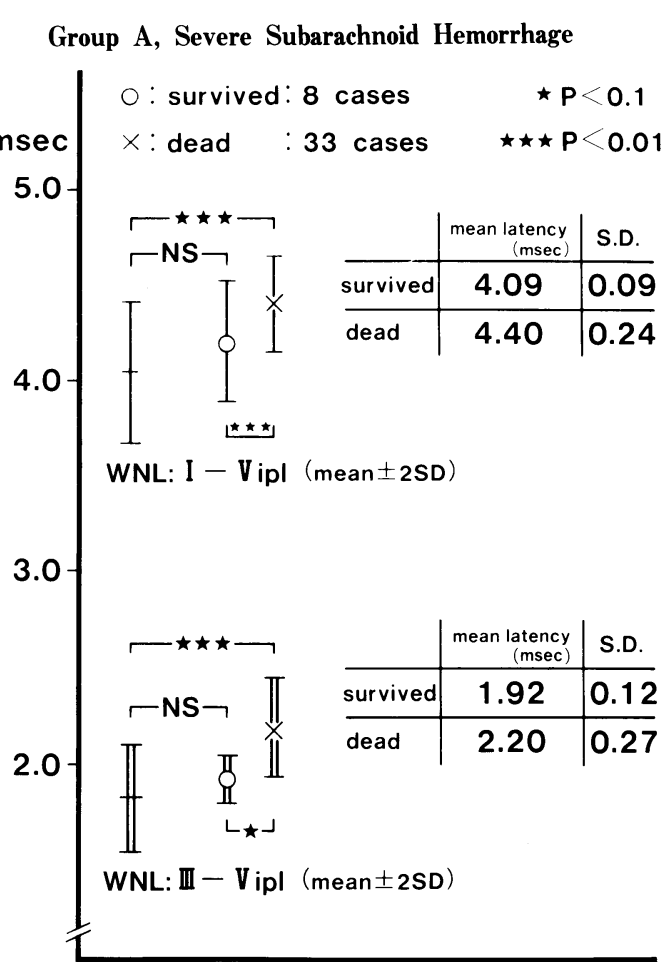

Fig. 1 Relationship between normal latencies and interpeak latencies of severe subarachnoid hemorrhage (Hunt \& Kosnik IV \& V). Interpeak latencies were significantly prolonged in the dead cases of subarachnoid hemorrhage patients $(p<0.01)$.

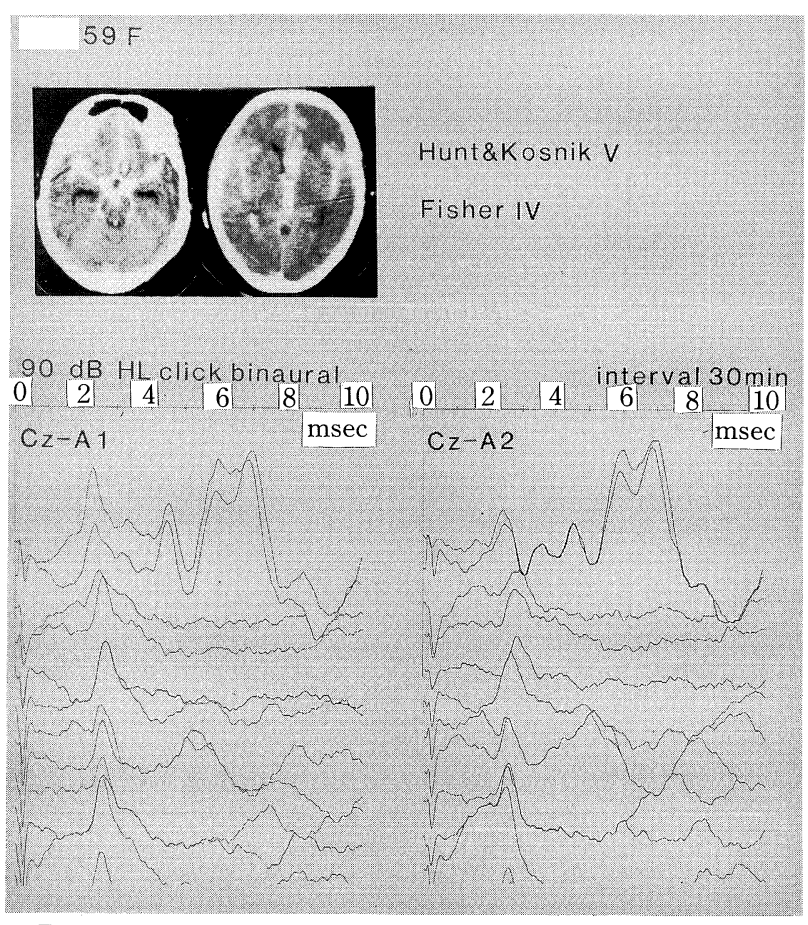

Fig. 2 A 59-year-old female case of severe subarachnoid hemorrhage. Interpeak latencies of initial BAEPs were prolonged. Sequential BAEPs showed progressive deterioration of the brainstem component. She was died a few days later. 


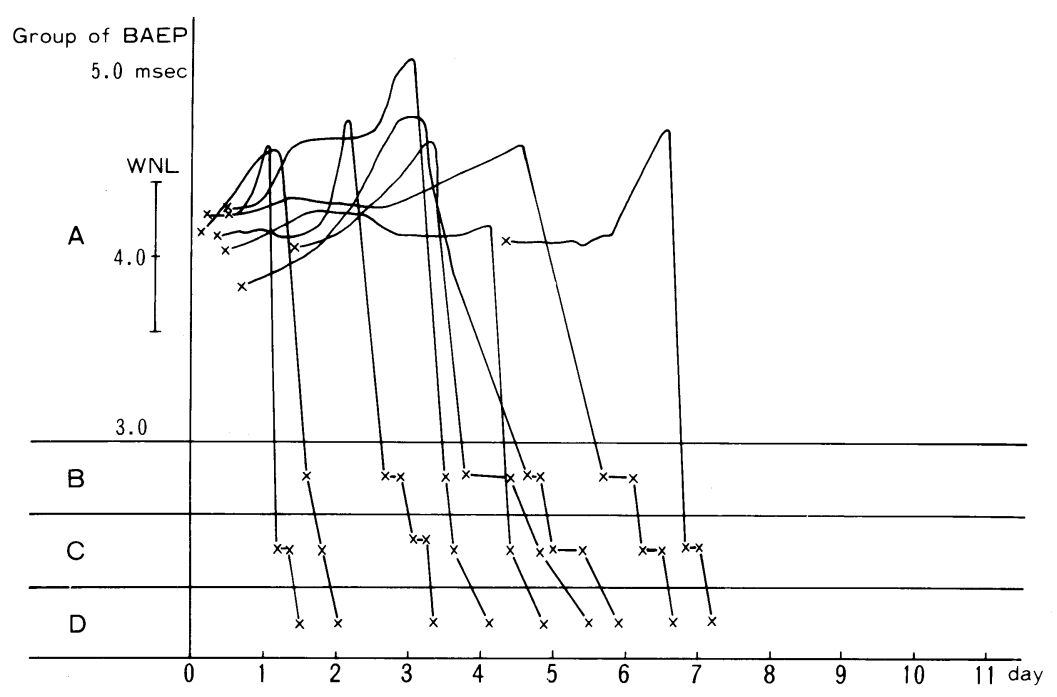

Fig. 3 Time course of I-V interpeak latencies in dead cases. All showed normal findings of initial BAEPs. In these cases interpeak latencies were progressively prolonged. After prolongation of I-V interpeak latency over normal limits, BAEPs immediately changed to Groups B,C, \& D. So sequential monitoring of BAEPs can be predictive for the prognosis of severe subarachnoid hemorrhage patients.

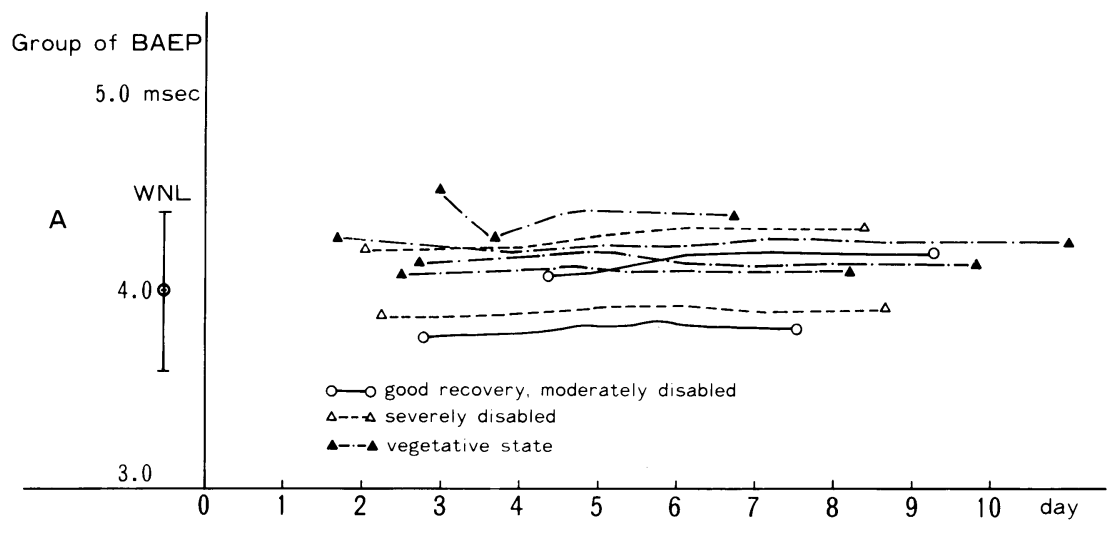

Fig. 4 Time course of I-V interpeak latencies in survival cases. No remarkable changes occurred in any cases in the following record.

閉鎖にて V 波潜時は短縮，延長を示している.したがっ て，急性水頭症による頭蓋内圧立進例では，脳室ドレナー ジの効果判定にも BAEP モニタリングは有用と思われる. そしてこのような症例の各潜時延長は, 頭蓋内圧方進によ る二次性脳幹障害によると考えられ，このような場合の潜 時延長所見は, 可逆的変化の限界を示唆していると考えら れた。

\section{考察}

われわれは，76例のクモ膜下出血重症例 (Hunt \& Kosnik grade IV, V) に対して, BAEP モニタリングを応用 し, その有用性を検討した. 今回の検討結果では, とくに
死亡群の BAEP の I-V ipl・III-V ipl が急性期から延長し 継時的変化でも急速な BAEP 所見の悪化を認めた.

さて，クモ膜下出血急性期死亡原因について，金子 ${ }^{4)}$ は, クモ膜下出血そのものによる脳幹障害が主因で, この時期 の剖検所見では, テント切痕ヘルニアや大後頭孔ヘルニア はまだ見られないとしている．また，急性期死亡例の CT と BAEP 所見を対比し, CT 上明らかな脳へルニア徴候 を認めないにもかかわらず, BAEP が脳幹障害を示す症

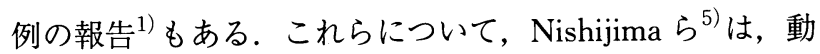
派瘤からの動脈性出血による脳幹の直接破壊と凝血塊によ る脳幹の絞扼を論じている，榊ら ${ }^{6)}$ は, 急性期クモ膜下出 血死の剖検所見から, 病理学的に脳幹部穿通動脈の急性変 


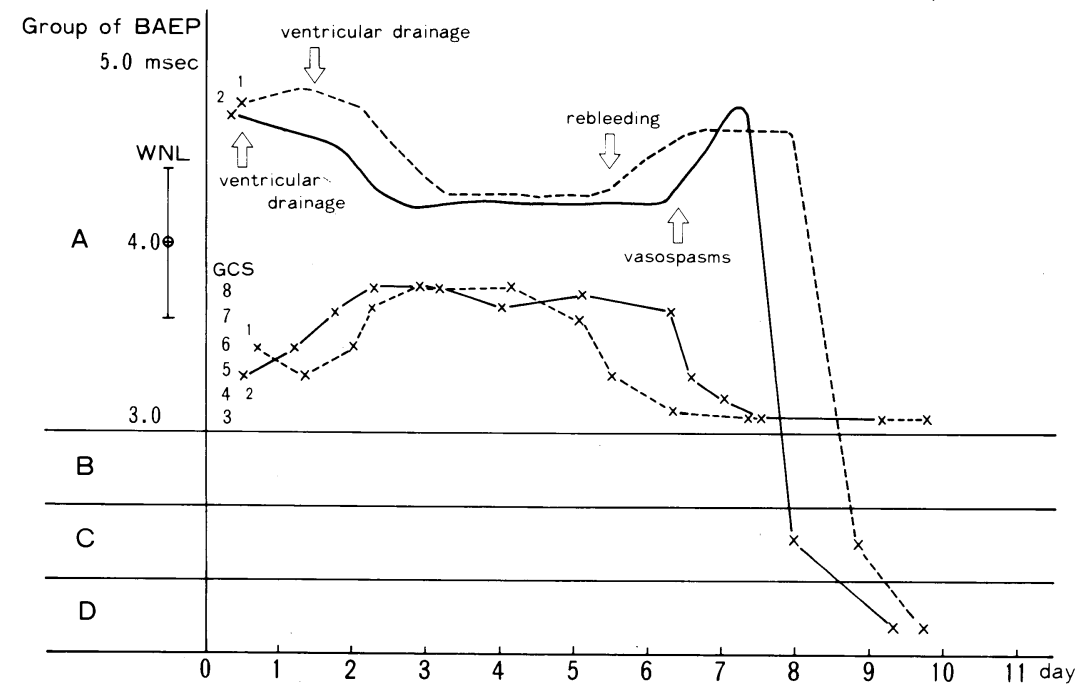

Fig. 5 Time course of I-V interpeak latencies and GCS of two ventricular drainage cases for acute hydrocephalus. I-V interpeak latencies become gradually shorter with improved consciousness level. After rebleeding or vasospasms BAEPs and GCS rapidly deteriolated. Sequential BAEP monitoring of these cases was useful for predicting the effect of ventricular drainage.

54 M Rt.callosomarginal a.aneurysm

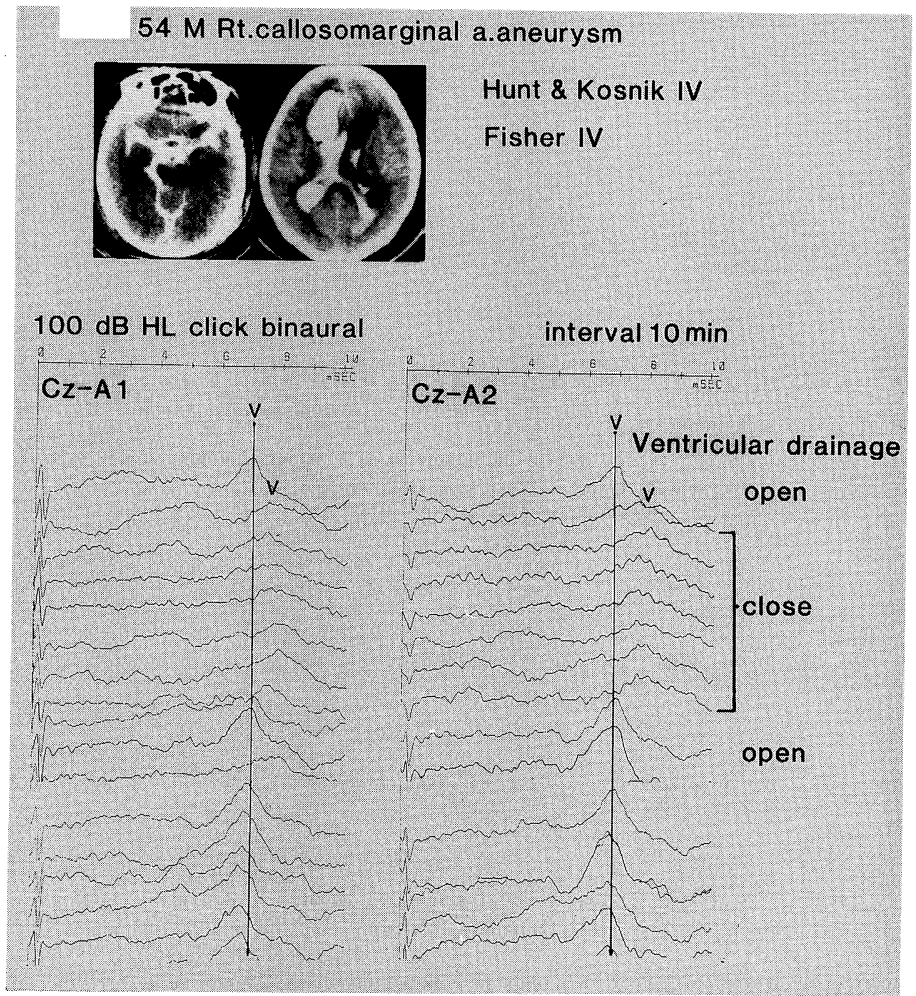

Fig. 6 A 54-year-old male. CT scan shows severe subarachnoid hemorrhage with intraventricular hemorrhage. When ventricular drainage was closed latency of the $\mathrm{Vth}$ wave was prolonged and amplitude was decreased, after opening of the drainage the $\mathrm{V}$ th wave was improved. 
性による脳幹の重篤な虚血性病巣の発生を挙げている.し たがって, クモ膜下腔の一定量以上の血腫や, その分解産 物のため脳幹実質の器質的, 機能的変化, 損傷が生ずるた めと考えられる. さらに, クモ膜下出血急性期の脳幹の破 壊, 虚血が cerebral vaso-moter paralysis を生じ, 脳血流 量の異常増加による急性脳腫脹と頭蓋内圧立進を招来する 7) とされる.

以上より, クモ膜下出血重症例では重症頭部外傷と同様 に一次性脳幹障害の存在が示唆され, 急性脳腫脹と頭蓋内 圧充進に伴う二次性脳幹障害が関与すると考えられる. A 群の死亡群および $\mathrm{B} ・ \mathrm{C} ・ \mathrm{D}$ 群では, これら重篤な一次性, 二次性脳幹障害が早期から加わったため予後不良であった と考えられる. そして, 急性期各潜時, とくに I-V ipl の mean +2 SD 以上の延長は予後不良の指標であった.

また, 脳室ドレナージによる減圧を行なった例で, 意識 レベルの変化と BAEP 各潜時の推移に相関を認めた。こ のことは実験的 ${ }^{8)}$ または臨床的検討 ${ }^{9}$ によっても，頭蓋内 圧六進によるテント切痕ヘルニアが進行している状態で, $\mathrm{BAEP}$ の IV, V 波の潜時が速やかな減圧で回復すること が報告されている.われわれの例も脳室ドレナージによる 二次性脳幹障害の改善を示したものと思われ, BAEPが 脳室ドレナージの効果判定にも応用できると考えられた.

\section{ま と め}

クモ膜下出血重症76例にBAEP モニタリングを応用し た. 生存群では I-V ipl, III-V ipl は継時的に正常範囲で 推移した. 一方, 初回 BAEP 波形が不良な B・C・D 群
の予後は絶対的に不良である。 また波形良好の A 群も， 初回または継時的に I-V ipl・III-V ipl が mean + 2 SD を 越える例は予後不良である.

水頭症合併例への脳室ドレナージにて BAEP 各潜時の 改善を認め, BAEP が脳室ドレナージの効果判定にも有 用と思われた.

\section{文献}

1）諌山和男：超急性期クモ膜下出血最重症例の検討. 日本医 大雑誌 53: 366-374, 1986

2) 河村弘庸, 花村 哲, 山田 修, ほか: 急性期重症脳障害 患者の予後判定. 脳神経外科 13: 1077-1085, 1985

3) Markand ON, Lee BI, Warren C, et al: Effect of hypothermia brainstem auditory evoked potentials in human. Ann Neurol 22: 507-513, 1987

4）金子満雄：脳神経外科における ICU 管理, 朝倉書店, 東京, 1984, pp 370-386

5) Nishijima $\mathrm{Y}$, Yoshimoto $\mathrm{T}$, Hori $\mathrm{S}$, et al: Cerebral Aneurysm, Neuron Publishing Co, Tokyo, 1979, pp 597-605

6）榊 三郎, 尾藤昭二 : くも膜下出血剖検症例の臨床病理学 的研究. 脳と神経 23: 143-151, 1971

7）長尾省吾, 角南典生, 筒井 巧, ほか：脳血管緊張に及ほ す脳幹部脳血管運動中枢の役割. 第 3 報. クモ膜下出血急 性期における脳幹破壊・刺激の頭蓋内圧に及ぼす影響. 脳 神経外科 14: $1250-1220,1986$

8）高家幹夫, 森竹浩三, 小西常起, ほか：誘発電位による脳 ヘルニアの病態把握ならびに予後判定に関する実験的研究. 脳神経外科 15: 743-749, 1987

9）佐々木勝, 坂本哲也, 山下雅知, ほか : 自動的かつ経時的 auditory evoked response (ABR) 測定. Neurol Med Chir (Tokyo) 25: 738-744, 1985 